\title{
Antioxidant and Hormone Responses to Heat Stress in Two Kentucky Bluegrass Cultivars Contrasting in Heat Tolerance
}

\author{
Feifei Li, Da Zhan, Lixin Xu, and Liebao Han ${ }^{1}$ \\ Turfgrass Research Institute, Beijing Forestry University, Beijing, P.R. China 100083 \\ Xunzhong Zhang ${ }^{1}$ \\ Department of Crop and Soil Environmental Sciences, Virginia Polytechnic Institute and State \\ University, Blacksburg, VA 24061
}

\begin{abstract}
AdDitional INDEX words. abscisic acid, indole-3-acetic acid, lipid peroxidation, superoxide dismutase, turfgrass
ABstract. Heat stress is a major limiting factor for growth of cool-season perennial grass species, and mechanisms of heat tolerance have not been well understood. This study was designed to investigate antioxidant enzyme and hormone metabolism responses to heat stress in two kentucky bluegrass (Poa pratensis L.) cultivars contrasting in heat tolerance. The plants were subjected to $20 / 20^{\circ} \mathrm{C}$ [day/night (control)] or $38 / 30{ }^{\circ} \mathrm{C}$ [day/night (heat stress)] for 28 days in growth chambers. Heat stress increased leaf electrolyte leakage (EL) and malondialdehyde (MDA) with heattolerant cultivar EverGlade exhibiting lower levels of EL and MDA relative to heat-sensitive cultivar Kenblue under heat stress. Superoxide dismutase (SOD) and catalase (CAT) activity increased and then declined during 28 days of heat stress. Peroxidase (POD) and ascorbate peroxidase (APX) activity declined and then increased during heat stress. 'EverGlade' had greater activities of SOD, CAT, POD, and APX relative to 'Kenblue' under heat stress. In addition, 'EverGlade' had two additional SOD isozymes and three additional POD isozymes relative to 'Kenblue' under heat stress. Leaf abscisic acid (ABA) increased in response to heat stress. Leaf indole-3-acetic acid (IAA) increased and then declined during heat stress. 'OverGlade' had higher ABA and IAA content relative to 'Kenblue'. At the end of heat stress, leaf IAA and ABA content were $27.8 \%$ and $73 \%$ higher in 'EverGlade' relative to 'Kenblue', respectively. The results indicated that antioxidant enzymes and the hormones (ABA and IAA) were associated with kentucky bluegrass heat tolerance. Selection and use of cultivars with higher IAA and ABA content and greater antioxidant enzyme activities may improve kentucky bluegrass growth and quality under heat stress.
\end{abstract}

Heat stress is one of the major limiting factors for coolseason perennial grasses in many regions. As a consequence of climate change and global warming, heat stress may have increasingly negative impact on crop growth and persistence. Plants have developed various systems to cope heat stress such as antioxidant defense system, hormonal regulation, saturation level of cell membrane lipid, and fatty acids (DiPaola and Beard, 1992; Fry and Huang, 2004). Antioxidants and hormones are some of the most important metabolic defense against heat stress (Upchurch, 2008; Wang et al., 2005; Wang and Huang, 2004).

Heat stress may inhibit photosynthesis and causes imbalance so that the energy absorbed through the light-harvesting complex exceeds what can be dissipated or transduced by photosystem II (Zhang and Ervin, 2008). Excess energy may be directed to $\mathrm{O}_{2}$ and result in accumulation of toxic reactive oxygen species (ROS) (Smirnoff, 1993). To limit oxidative damage under stress conditions, plants have developed a series of detoxification systems that break down the highly toxic ROS (Larkindale and Huang, 2004). Superoxide dismutase constitutes the first line of defense against ROS by dismutating the superoxide anion to hydrogen peroxide $\left(\mathrm{H}_{2} \mathrm{O}_{2}\right)$. Next, $\mathrm{H}_{2} \mathrm{O}_{2}$ is finely regulated by CAT and an array of peroxidases localized in almost all compartments of the plant cell such as APX (Blokhina et al., 2003). Heat-induced oxidative stress has been

Received for publication 13 May 2014. Accepted for publication 10 July 2014. This research was supported by Forestry Bureau of China ( 948 project No. 2011-4-50) and the National Science Foundation of China (No. 31172255).

1Corresponding authors. E-mail: hanliebao@163.com, xuzhang@vt.edu. reported in creeping bentgrass [Agrostis stolonifera L. (Liu and Huang, 2000)], tall fescue [Festuca arundinacea (Schreb.) (Cui et al., 2006)], and kentucky bluegrass (Jiang and Huang, 2001). Liu and Huang (2000) found the activities of SOD and CAT decreased and POD activity increased in both leaves and roots of creeping bentgrass during heat stress. Jiang and Huang (2001) reported heat stress reduced the activities of APX, CAT, and glutathione reductase in tall fescue and kentucky bluegrass. Cultivar variations in antioxidant enzyme activities were associated with the differences in heat tolerance of turfgrasses and indicated a positive correlation between chlorophyll content and the antioxidant enzymes and a negative correlation between membrane injury index and the antioxidant enzymes (Almeselmani et al., 2006; Cui et al., 2006; Huang and Gao, 2001). In addition, changes in the amount of a particular isoform of an antioxidant enzyme can be more important than alterations in the total activity (Mullineaux and Creissen, 1997). Pinhero et al. (1997) have suggested that synthesis of new antioxidant enzyme isoforms could be more beneficial for antioxidant metabolism than mere enhancement of the activity.

There is increasingly evidence showing that hormone metabolism may play an important role in stress tolerance (Liu et al., 2002; Zhang et al., 2009). ABA and IAA are hormones that mediate signaling events involved in plant adaptation to stress and senescence. IAA is the primary auxin in the majority of plant species. The evidence on the role of IAA in heat resistance is very contradictory. For a long time, it was generally assumed that heat results in a decrease in IAA content (Pustovoitova and 
Zholkevich, 1992). However, there are evidences showing the adaptation to heat is accompanied by an increase in the IAA content (Tang and Zheng, 2008; Weiler et al., 1981). ABA plays a regulatory role in controlling stomatal aperture under heat stress (Strivastava, 2002). Rapid ABA accumulation has been observed when plants are subjected to drought, salinity, and extreme temperatures (Xiong et al., 2002). Larkindale and Huang (2004) determined that in creeping bentgrass, ABA level did not rise during heat stress, but it accumulated on recovery from stress. However, the interrelation between the changes in hormone (IAA and ABA) metabolism and the development of adaptation to high temperature in perennial grass species is largely unknown.

Kentucky bluegrass is a cool-season perennial grass species widely used for home lawns and commercial landscapes in temperate climates. The optimum temperature for shoot growth of cool-season grasses ranges from 15 to $23{ }^{\circ} \mathrm{C}$ (Beard, 1973). However, temperatures in the U.S. transitional zone often approach $35^{\circ} \mathrm{C}$ or higher during summer months. Heat stress is a major factor limiting growth of cool-season grasses in the warm climatic regions. The mechanisms of heat tolerance associated with antioxidant and hormone metabolism in cool-season perennial grass species have not been well understood. Little studies are reported on heat stress-induced changes in the isoform patterns of antioxidant enzymes in cool-season turfgrasses. Understanding the physiological mechanisms of turfgrass heat tolerance is important for breeders to develop heat-tolerant cultivars and turfgrass practitioners to improve turfgrass quality under heat stress. The objectives of this study were to investigate antioxidant enzymes and hormone metabolism of the two kentucky bluegrass cultivars (EverGlade and Kenbule) contrasting in heat tolerance and to examine if variation between the cultivars differing in heat tolerance is associated with antioxidant enzymes and hormone metabolism.

\section{Materials and Methods}

Plant materials and growth Conditions. Two kentucky bluegrass cultivars (EverGlade and Kenblue) were planted in plastic pots (16 cm diameter, $15 \mathrm{~cm}$ deep) filled with silt loam soil (fine-loamy, mixed mesic Typic Hapludult) mixed with a small amount of sand (3:1) at a seeding rate of $15 \mathrm{~g} \cdot \mathrm{m}^{-2}$ pure live seeds. 'Kenblue' is relatively heat-sensitive and 'EverGlade' is a heat-tolerant cultivar based on the results from our previous study (Zhan et al., 2012). Plants were grown in a greenhouse with temperatures at $20 / 20{ }^{\circ} \mathrm{C}$ (day/night), $70 \%$ relative humidity, $12-\mathrm{h}$ photoperiod, and photosynthetically active radiation $(P A R)$ at $400 \mu \mathrm{mol} \cdot \mathrm{m}^{-2} \cdot \mathrm{s}^{-1}$. The plants were grown for $65 \mathrm{~d}$ from 2 Apr. to 7 June 2011 and then moved into growth chambers (PRX model; Saifu Instrument Co., Ningbo, Zhejiang, P.R. China). The growth chambers were set at $20 / 20{ }^{\circ} \mathrm{C}$ (day/night), $75 \%$ relative humidity, $14-\mathrm{h}$ photoperiod, and $P A R$ at $400 \mu \mathrm{mol} \cdot \mathrm{m}^{-2} \cdot \mathrm{s}^{-1}$. The plants were fertilized at $2.5 \mathrm{~g} \cdot \mathrm{m}^{-2}$ nitrogen $(\mathrm{N})$ per month, trimmed at $7.5 \mathrm{~cm}$ tall, and irrigated by hand until water drainage from the bottom of the pots three times per week.

Heat stress treatments. The plants were grown in the growth chambers for $54 \mathrm{~d}$ and trimmed at the canopy height of $10 \mathrm{~cm}$ weekly. On 1 Aug. 2011, eight pots of plants (four pots for each cultivar) were maintained at $20^{\circ} \mathrm{C}$ as control plants ( $0 \mathrm{~d}$ of heat stress), whereas another set of eight pots of plants (four pots for each cultivar) was exposed to $38 / 30{ }^{\circ} \mathrm{C}$ (day/night). Plants were watered once a day to avoid water deficit.

Plants were treated under heat stress for $28 \mathrm{~d}$ between 1 and 28 Aug. 2011. Leaf samples were collected at $0 \mathrm{~d}$ (control at $\left.20{ }^{\circ} \mathrm{C}\right), 7,14,21$, and $28 \mathrm{~d}$ of heat stress treatment. Fresh leaf samples were collected and a small portion of each sample was used to measure EL. The rest of the fresh leaf sample for analysis of MDA, proline, antioxidant enzymes, and hormones was frozen in liquid $\mathrm{N}$ and kept at $-70{ }^{\circ} \mathrm{C}$ before final analysis.

Heat injury determination. Cell membrane EL has been used as an indicator of the membrane stability. For EL analysis, fresh leaves $(0.1 \mathrm{~g})$ were rinsed and immersed in $20 \mathrm{~mL}$ deionized water. The leaf samples were shaken for $24 \mathrm{~h}$ and then electrical conductance $\left(\mathrm{C}_{\text {initial }}\right)$ was measured. The leaf samples were then killed by autoclaving at $140{ }^{\circ} \mathrm{C}$ for $20 \mathrm{~min}$. The electrical conductivity $\left(\mathrm{C}_{\max }\right)$ was measured after the samples were cooled down to room temperature. Relative EL was calculated as the percentage of $\mathrm{C}_{\text {initial }}$ over $\mathrm{C}_{\max }$ (Blum and Ebercon, 1981).

Membrane lipid peroxidation was determined based on MDA content. The MDA was measured according to Hodges et al. (1999). Leaf samples $(0.5 \mathrm{~g})$ were homogenized in $10 \mathrm{~mL}$ $10 \%$ trichloroacetic acid (TCA) and centrifuged at $12,000 g_{n}$ for $20 \mathrm{~min}$. Then $2 \mathrm{~mL} 0.6 \%$ thiobarbituric acid in $10 \%$ TCA was added to $2 \mathrm{~mL}$ supernatant. The mixture was heated in boiling water for $30 \mathrm{~min}$ and then quickly cooled in an ice bath. After centrifugation at $1600 \mathrm{~g}_{\mathrm{n}}$ for $10 \mathrm{~min}$, the absorbance of the mixture at 450, 532, and $600 \mathrm{~nm}$ was determined. The concentration of MDA was calculated using MDA's extinction coefficient of $155 \mathrm{mM}^{-1} \cdot \mathrm{cm}^{-1}$.

Antioxidant Enzyme activity. Frozen leaf samples $(0.25 \mathrm{~g})$ were ground in liquid $\mathrm{N}_{2}$ and extracted in $4 \mathrm{~mL}$ of ice-cold 50 mmol sodium phosphate buffer ( $\mathrm{pH} 7.0$ ) containing $0.2 \mathrm{~mm}$ ethylenediamine-tetraacetic acid (EDTA) and 1\% polyvinylpyrrolidone in an ice-water bath. The homogenate was centrifuged at $15,000 \mathrm{~g}_{\mathrm{n}}$ for $20 \mathrm{~min}$ at $4^{\circ} \mathrm{C}$. Supernatant was used to measure SOD, CAT, POD, and APX activities.

Superoxide dismutase activity was determined by measuring its ability to inhibit the photochemical reduction of nitro blue tetrazolium (NBT) according to the method of Giannopolitis and Ries (1977) with slight modifications. The reaction solution (3 mL) contained $50 \mathrm{~mm}$ phosphate buffer $(\mathrm{pH} 7.8), 0.1 \mathrm{~mm}$ EDTA, $13 \mathrm{~mm}$ methionine, $65 \mu \mathrm{M}$ NBT and $1.3 \mu \mathrm{M}$ riboflavin, and $30 \mu \mathrm{L}$ SOD extract. A solution containing no enzyme solution was used as the control. Test tubes were irradiated under fluorescent lights $\left(60 \mu \mathrm{mol} \cdot \mathrm{m}^{-2} \cdot \mathrm{s}^{-1}\right)$ at $25^{\circ} \mathrm{C}$ for $10 \mathrm{~min}$. The absorbance of each solution was measured at $560 \mathrm{~nm}$ using a spectrophotometer, and one unit of enzyme activity was defined as the amount of enzyme that would inhibit $50 \%$ of NBT photoreduction.

Activities of CAT and POD were determined using the method of Chance and Maehly (1995) with modifications. For CAT, the reaction solution $(3 \mathrm{~mL})$ contained $50 \mathrm{~mm}$ phosphate buffer ( $\mathrm{pH} 7.0$ ), $15 \mathrm{~mm} \mathrm{H}_{2} \mathrm{O}_{2}$, and $100 \mu \mathrm{L}$ of extract. The reaction was initiated by adding the enzyme extract. Changes in absorbance at $240 \mathrm{~nm}$ were read once every $1 \mathrm{~min}$ within the first 3 min using a spectrophotometer. One unit of CAT activity was defined as the absorbance change of 0.01 units per minute. For POD analysis, the $3-\mathrm{mL}$ reaction mixture contained $1 \mathrm{~mL}$ $50 \mathrm{~mm}$ phosphate buffer $(\mathrm{pH} 7.0), 0.95 \mathrm{~mL} 0.2 \%$ guaiacol solution, and $50 \mu \mathrm{L}$ enzyme extract. The reaction was started 

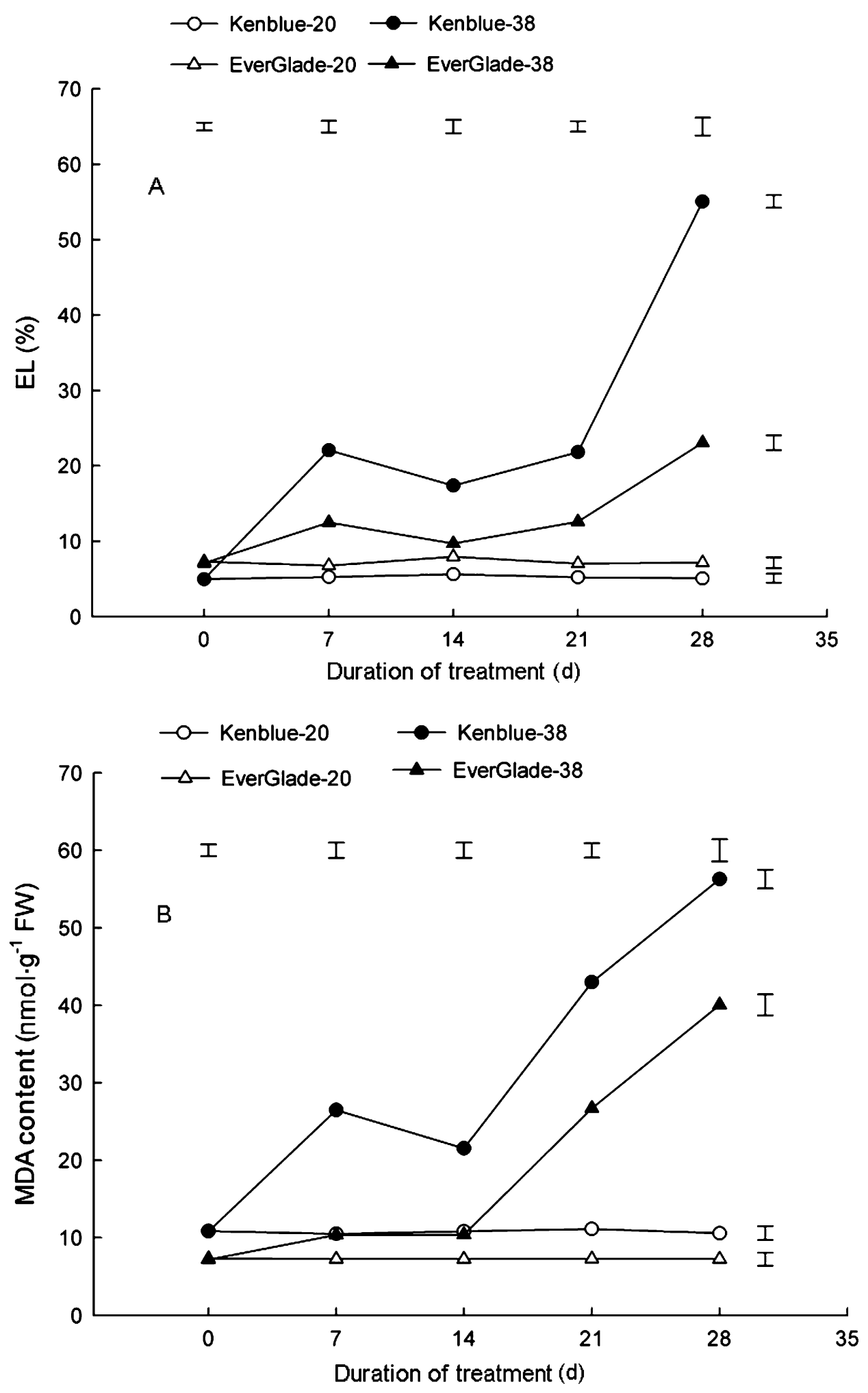

Fig. 1. Changes in leaf electrolyte leakage [EL (A)] and malondialdehyde (MDA) content (B) of two kentucky bluegrass cultivars during heat stress. Bars on the top indicate least significant difference (LSD) values $(P=0.05, \mathrm{n}=4)$ for comparison among cultivars and on the right represent LSD values for comparison between duration of heat stress for a given cultivar. Kenblue-20 and Kenblue-38 indicate 'Kenblue' under normal condition and heat stress, respectively; EverGlade-20 and EverGlade-38 indicate 'EverGlade' under normal condition and heat stress, respectively.

with $1 \mathrm{~mL} 0.3 \% \mathrm{H}_{2} \mathrm{O}_{2}$. Reading at $470 \mathrm{~nm}$ was recorded once every $1 \mathrm{~min}$ within the first $3 \mathrm{~min}$.

The activity of APX was detected using the method of Zhang et al. (2005). The reaction solution $(3 \mathrm{~mL})$ contained
$2.82 \mathrm{~mL} 50 \mathrm{~mm}$ phosphate buffer (pH 7.0), $0.5 \mathrm{~mm}$ ascorbate, $0.1 \mathrm{~mm}$ EDTA, and $100 \mu \mathrm{L}$ enzyme extract. The reaction was started with addition of $30 \mu \mathrm{L} 10 \mathrm{mM} \mathrm{H}_{2} \mathrm{O}_{2}$. The absorbance of the solution was determined at $290 \mathrm{~nm}$ after $1 \mathrm{~min}$. One unit of APX activity was defined as the absorbance change of 0.1 units per minute.

Antioxidant isozymes. The procedure of protein extraction was the same as for antioxidant enzyme. The extracts $(15 \mu \mathrm{L})$ for SOD, CAT, and POD were loaded on each gel. Native polyacrylamide gel electrophoresis (PAGE) was performed using a Mini-Protean system (Bio-Rad Laboratories, Hercules, CA) at $4{ }^{\circ} \mathrm{C}$, $120 \mathrm{~V}$ for $90 \mathrm{~min}$, except that sodium dodecyl sulphate was omitted. For SOD and POD, enzyme extracts were subjected to native PAGE with 10\% resolving gel and 3\% stacking gel and CAT was detected on $7 \%$ resolving gel and 4\% stacking gel.

The total activity of SOD was revealed using the method of Beauchamp and Fridovich (1971) with some modifications. The gels were incubated in $50 \mathrm{~mm}$ potassium phosphate buffer ( $\mathrm{pH}$ 7.5) containing $2.5 \mathrm{~mm}$ NBT in the dark for $25 \mathrm{~min}$. After briefly being washed twice with the same buffer, the gels were soaked in $50 \mathrm{~mm}$ potassium phosphate buffer ( $\mathrm{pH}$ 7.5) containing $30 \mu \mathrm{M}$ riboflavin and $0.4 \%$ $\mathrm{N}, \mathrm{N}, \mathrm{N}, \mathrm{N}$-tetramethylethylenediamine in the dark for $40 \mathrm{~min}$. The gels were then illuminated for $10 \mathrm{~min}$ with gentle agitation until appearance of enzyme bands and were transferred to $1 \%(\mathrm{v} / \mathrm{v})$ acetic acid to stop the reaction.

The CAT isozyme staining was performed according to $\mathrm{He}$ and Huang (2010) and Woodbury et al. (1971) with modifications. After finishing the running, the gel was washed in three changes of distilled water for a total of $\approx 6 \mathrm{~min}$ to remove the buffer from the gel surface where staining occurred. The gels were incubated in $5 \mathrm{mM} \mathrm{H}_{2} \mathrm{O}_{2}$ for $10 \mathrm{~min}$ in the dark and then in the stain mixture containing $1 \%(\mathrm{w} / \mathrm{v})$ potassium ferricyanide $\left\{\mathrm{K}_{3}\left[\mathrm{Fe}\left(\mathrm{CN}_{6}\right)\right]\right\}$ and $1 \%$ $(\mathrm{w} / \mathrm{v})$ ferric chloride $\left(\mathrm{FeCl}_{3}\right)$ [equal volume of $2 \%(\mathrm{w} / \mathrm{v})$, added sequentially] until the light yellow bands (CAT isoenzymes) were visible.

The activity of POD was detected using the method of Fielding and Hall (1978). The gels were soaked in a sodium 

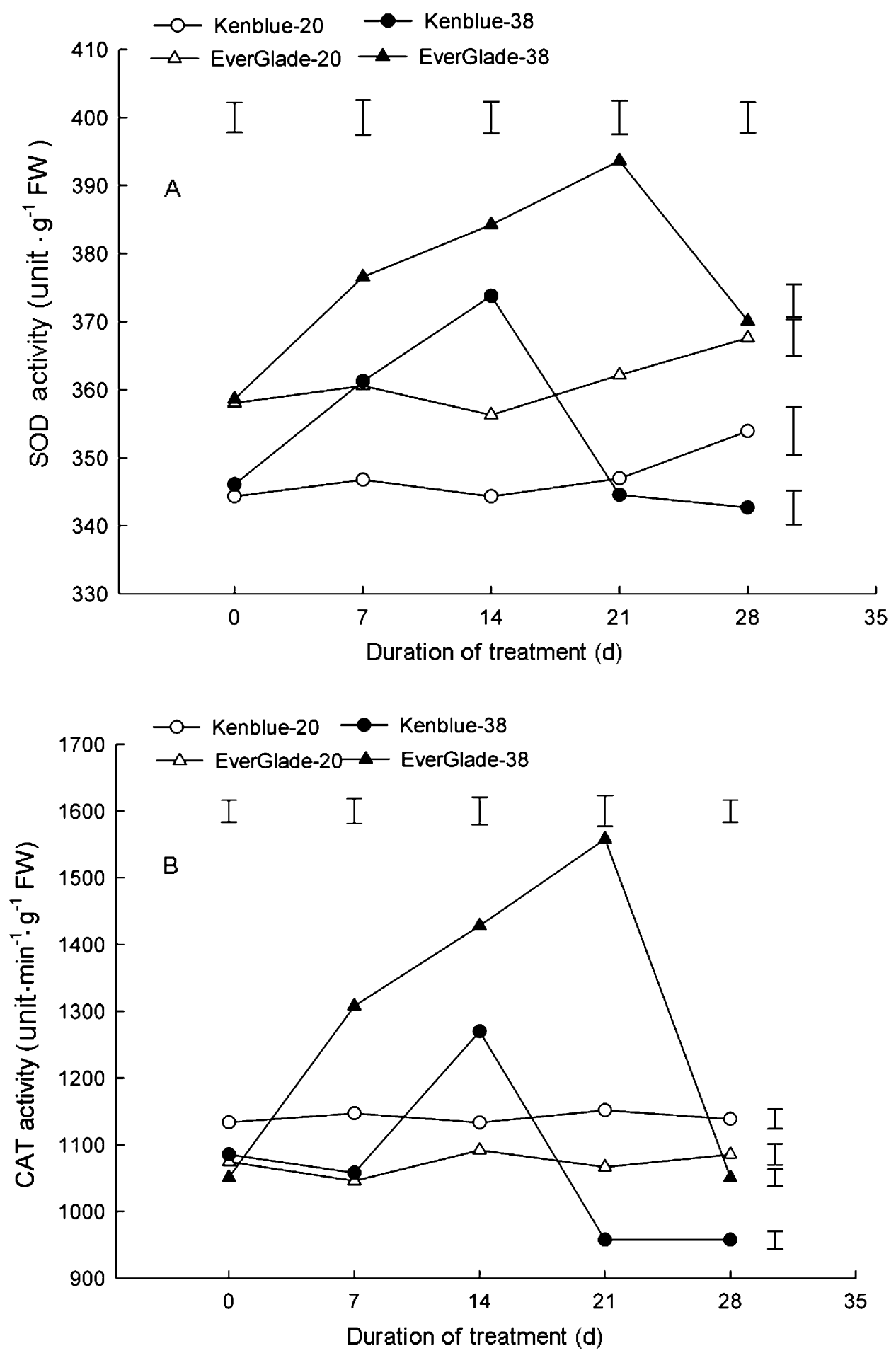

Fig. 2. Changes in leaf superoxide dismutase [SOD (A)] and catalase [CAT (B)] activity of two kentucky bluegrass cultivars during heat stress. Bars on the top indicate least significant difference (LSD) values $(P=0.05, \mathrm{n}=4)$ for comparison among cultivars and on the right represent LSD values for comparison between duration of heat stress for a given cultivar. Kenblue-20 and Kenblue-38 indicate 'Kenblue' under normal condition and heat stress, respectively; EverGlade-20 and EverGlade-38 indicate 'EverGlade' under normal condition and heat stress, respectively.

phosphate solution $(10 \mathrm{~mm}$ sodium phosphate and $150 \mathrm{~mm}$ sodium chloride, $\mathrm{pH}$ 6.0) for 45 min to lower the $\mathrm{pH}$. After briefly being washed with $100 \mathrm{~mm}$ potassium phosphate buffer ( $\mathrm{pH}$ 6.4), the gels were stained in $100 \mathrm{~mm}$ potassium phosphate buffer ( $\mathrm{pH}$ 6.4) containing $20 \mathrm{~mm}$ guaiacol and $5.55 \mathrm{mM} \mathrm{H}_{2} \mathrm{O}_{2}$ for 5 to $10 \mathrm{~min}$ until the bands were clearly visible. The gels were then washed with distilled water to stop the reaction.

Leaf ABA and IAA. The leaf IAA and ABA were extracted according to Edlund et al. (1995) and Zhang et al. (2009) with some modifications. Leaf tissue $(1 \mathrm{~g})$ was ground with a mortar and pestle in liquid $\mathrm{N}$ and extracted in $6 \mathrm{~mL} \mathrm{Na-}$ phosphate buffer $(0.05 \mathrm{M}, \mathrm{pH} 7.0)$ containing $0.02 \%$ sodium diethyldithiocarbamate as an antioxidant and the hormones were extracted for $2 \mathrm{~h}$ at $4{ }^{\circ} \mathrm{C}$ with shaking. The homogenate was centrifuged at $10,000 g_{\text {n }}$ for $10 \mathrm{~min}$ at $4{ }^{\circ} \mathrm{C}$. The supernatant was kept for further analysis. The pellet repeated this operation. The supernatant was transferred into test tubes and $\mathrm{pH}$ was adjusted to 2.6 with $1.0 \mathrm{M} \mathrm{HCl}$. The sample was slurried with polymeric resin (Amberlite XAD-7; Sigma-Aldrich, St. Louis, MO) for $1 \mathrm{~h}$ with shaking. After removal of the buffer, the XAD-7 was washed two times with $3 \mathrm{~mL}$ of $1 \%$ acetic acid before being slurried two times with $3 \mathrm{~mL}$ dichloromethane for $1 \mathrm{~h}$ at $4{ }^{\circ} \mathrm{C}$ with shaking (Edlund et al., 1995). The combined dichloromethane fractions were reduced to dryness with $\mathrm{N}$ gas. Then samples were dissolved in $200 \mu \mathrm{L}$ methanol and $200 \mu \mathrm{L} 0.075 \%$ acetic acid and filtered using an acrodisc $13-\mathrm{mm}$ syringe filter with a $0.2-\mathrm{mm}$ nylon membrane (Fisher Scientific Co., Pittsburgh, PA) and then analyzed using the high-performance liquid chromatography system (Agilent, Santa Clara, CA) according to the methods of Wang et al. (2008) with some modifications (Man et al., 2011). An aliquot $(200 \mu \mathrm{L})$ of the filtered samples was injected into a Shim-Park C18 VP-ODS chromatographic column $(150 \mathrm{~mm} \times$ $4.6 \mathrm{~mm}, 5 \mu \mathrm{m}$; Shimadzu America, Columbia, MD) with gradient elution at a flow rate of $1 \mathrm{~mL} \cdot \mathrm{min}^{-1}$ at $30{ }^{\circ} \mathrm{C}$ using methanol and $0.075 \%$ acetic acid as a mobile phase from 10:90 (v/v) to 90:10 (v/v). Detection of ABA and IAA was carried out at $254 \mathrm{~nm}$ by a Shimazu SPD10A VP ultraviolet detector and cochromatography with authentic standards (Sigma-Aldrich). The time of appearance of peak and the wavelength ( $280 \mathrm{~nm}$ for IAA and $262 \mathrm{~nm}$ for ABA) of 



Fig. 3. Changes in peroxidase [POD (A)] and ascorbate peroxidase [APX (B)] activity of two kentucky bluegrass cultivars during heat stress. Bars on the top indicate least significant difference (LSD) values $(P=0.05, \mathrm{n}=4)$ for comparison among cultivars and on the right represent LSD values for comparison between duration of heat stress for a given cultivar. Kenblue-20 and Kenblue-38 indicate 'Kenblue' under normal condition and heat stress, respectively; EverGlade-20 and EverGlade-38 indicate 'EverGlade' under normal condition and heat stress, respectively.

characteristic absorbance of ABA and IAA were determined with authentic standard compounds, respectively (Wang et al., 2008). All values were corrected against internal standards with known concentrations of different hormones.
EXPERIMENTAL DESIGN AND STATISTICAL ANALYSIS. A split plot design was used with temperature regime as the main plot and cultivars as the subplot. Two sets of growth chambers were used with one set for control with temperature setting at $20 / 20{ }^{\circ} \mathrm{C}$ (day/night) and the other set for heat stress treatment at $38 / 30^{\circ} \mathrm{C}$ (day/night). Each of four pots (replicates) was randomly arranged inside each set of growth chamber. There were four replicates for each treatment. The parameters were measured for three leaf subsamples taken from each pot. The mean of three subsamples was used to represent a single replicate in the analysis of variance (ANOVA). Effects of temperature, cultivar, and their interactions were analyzed with ANOVA according to the general linear model using SPSS for Window software (Version 16.0 for Windows; IBM Corp., Armonk, $\mathrm{NY}$ ) and the interactions for the measurements were found significant $(P<0.05)$. One-way ANOVA was used to determine the effects of sampling date. Mean separations were performed with the Fisher's protected least significance difference test at $P=0.05$.

\section{Results}

LEAF EL AND MDA CONTENT. The EL increased in response to heat stress in both cultivars with a dramatic increase being observed at $28 \mathrm{~d}$ (Fig. 1A). 'Kenblue' had a greater EL than 'EverGlade' at all sampling dates except for $0 \mathrm{~d}$. The EL in 'Kenblue' was 58\% greater than that in 'EverGlade' at $28 \mathrm{~d}$. No difference in EL between the two cultivars was found at normal temperature conditions.

MDA content increased in response to heat stress in both cultivars (Fig. 1B). Greater MDA content 'Kenblue' relative to 'EverGlade' was observed in all sampling dates. The MDA content in 'Kenblue' was $28.8 \%$ greater than in 'EverGlade' at $28 \mathrm{~d}$. No differences were observed between the two cultivars under normal conditions.

Antioxidant EnZYMe activity. The SOD activity increased from 7 to $14 \mathrm{~d}$ in 'Kenblue' and from 0 to $21 \mathrm{~d}$ in 'EverGlade' and declined thereafter in response to heat stress (Fig. 2A). 'EverGlade' had greater SOD activity relative to 'Kenblue' at 
all sampling dates. The SOD activity in 'EverGlade' was $8.0 \%$ higher than that in 'Kenblue' at $28 \mathrm{~d}$. Under normal conditions, 'EverGlade' also had greater SOD activity than 'Kenblue' at all sampling dates (Fig. 2A).

The CAT activity increased from 0 to $21 \mathrm{~d}$ in 'EverGlade' and from 0 to $14 \mathrm{~d}$ in 'Kenblue' and declined thereafter in response to heat stress (Fig. 2B). 'EverGlade' had greater CAT activity relative to 'Kenblue' at all sampling dates except for $0 \mathrm{~d}$. At $28 \mathrm{~d}$, the CAT activity in 'EverGlade' was 9.7\% greater than that in 'Kenblue'. Under normal conditions, 'Kenblue' had higher CAT activity than 'EverGlade' only at $7 \mathrm{~d}$ (Fig. 2B).

The POD activity declined from 0 to $7 \mathrm{~d}$ in 'EverGlade' or from 0 to $14 \mathrm{~d}$ in 'Kenblue' and then increased thereafter in response to heat stress (Fig. 3A). 'EverGlade' had greater POD activity than 'Kenblue' at all sampling dates. At 28 d, the POD activity in 'EverGlade' was $35.1 \%$ greater than that in 'Kenblue' under heat stress. Under normal conditions, 'EverGlade' had higher POD activity than 'Kenblue' at 0, 14, and $21 \mathrm{~d}$ (Fig. 3A).

The APX activity increased in response to $28 \mathrm{~d}$ of heat stress in both cultivars (Fig. 3B). Heat stress caused an increase in APX activity by 1.5-fold in 'Kenblue' and 2.9-fold in 'EverGlade', respectively, as measured at $28 \mathrm{~d}$. At $0 \mathrm{~d}$, APX activity in 'EverGlade' was 20.1\% lower than that in 'Kenblue'; at $28 \mathrm{~d}$ of heat stress, the APX activity in 'EverGlade' was $55.6 \%$ greater than that in 'Kenblue'. Under normal conditions, however, 'Kenblue' had higher APX activity than 'EverGlade' (Fig. 3B).

Antioxidant Isozymes. 'Kenblue' had four SOD isozymes and 'EverGlade' had six SOD isozymes under heat treatment. SOD5 and SOD6 were revealed through the native PAGE gel in 'EverGlade' but their intensity decreased at $28 \mathrm{~d}$ of heat stress (Fig. 4).

Only one isoform of CAT was identified in both cultivars (Fig. 5). More and stronger CAT isozymes were detected in 'EverGlade' than in 'Kenblue'. The intensity of CAT1 decreased at $28 \mathrm{~d}$ of heat stress (Fig. 5). Two POD isozymes were detected in 'Kenblue' and five POD isozymes were found in 'EverGlade' (Fig. 6).

LEAF ABA AND IAA Content. The leaf ABA content increased in response to heat stress in both cultivars with a greater increase being found in 'EverGlade' relative to 'Kenblue' (Fig. 7A). 'EverGlade' had greater ABA content relative to 'Kenblue' at all sampling dates under heat stress. The ABA content in 'EverGlade' was 73\% higher than that in 'Kenblue' at $28 \mathrm{~d}$. Under normal conditions, leaf ABA content was similar in both cultivars (Fig. 7A).

The leaf IAA content increased from 0 to $14 \mathrm{~d}$ and then declined in 'EverGlade'. In contrast, IAA content remained unchanged from 0 to $21 \mathrm{~d}$ and then declined in 'Kenblue' during heat stress (Fig. 7B). IAA content was higher in 'EverGlade' relative to 'Kenblue' under either heat stress or optimal conditions at all sampling dates (Fig. 7B). The IAA content 'EverGlade' was $27.8 \%$ higher than that in 'Kenblue' at $28 \mathrm{~d}$.

\section{Discussion}

The results of this study indicated that heat stress $\left[38 / 20^{\circ} \mathrm{C}\right.$ (day/night)] caused damage to kentucky bluegrass as indicated by increased EL and MDA. The initial increase in MDA content occurred from 0 to $7 \mathrm{~d}$ for 'Kenblue' and from 14 to $21 \mathrm{~d}$ for 'EverGlade'. 'EverGlade' had lower EL and MDA relative to
A

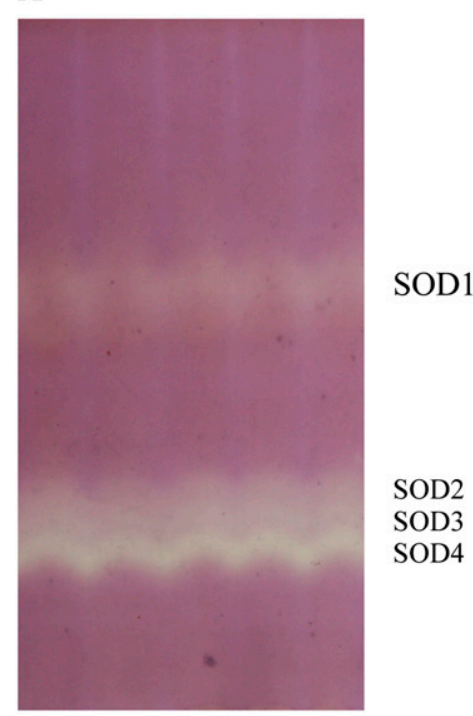

B

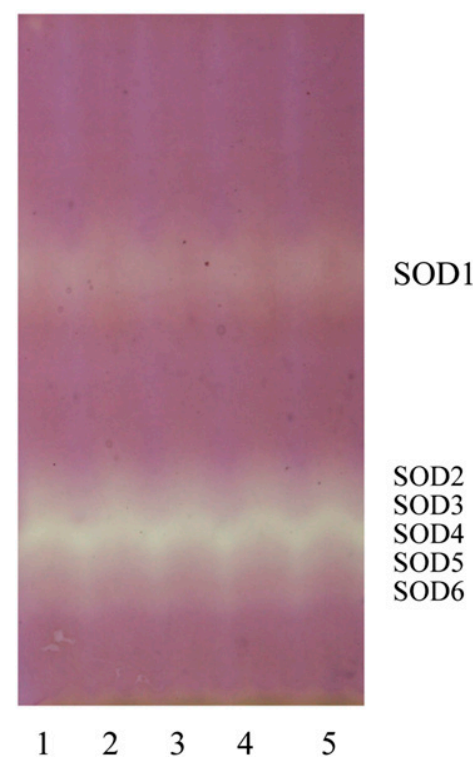

Fig. 4. Changes in superoxide dismutase (SOD) isoforms of 'Kenblue' (A) and 'EverGlade' (B) kentucky bluegrass during heat stress. Equal amounts $(15 \mu \mathrm{L})$ were loaded in each lane: lane $1=20^{\circ} \mathrm{C}(0 \mathrm{~d}$ of heat stress $)$, lane $2=38 / 30^{\circ} \mathrm{C}$ for $7 \mathrm{~d}$, lane $3=38 / 30{ }^{\circ} \mathrm{C}$ for $14 \mathrm{~d}$, lane $4=38 / 30{ }^{\circ} \mathrm{C}$ for $21 \mathrm{~d}$, lane $5=38 / 30{ }^{\circ} \mathrm{C}$ for $28 \mathrm{~d}$.

'Kenblue'. This suggests that 'EverGlade' had less oxidative damage and maintained relatively better membrane stability relative to 'Kenblue' under heat stress.

The results of this study showed that SOD and CAT activity increased and then declined, whereas POD and APX decreased and then increased during $28 \mathrm{~d}$ of heat stress. 'EverGlade' had higher activities of SOD, CAT, POD, and APX relative to 'Kenblue' under heat stress at most sampling dates (Figs. 2 and 3). This is consistent with the results from previous studies by Cui et al. (2006) and Liu et al. (2002) who found that heat-tolerant turfgrass cultivars or species had higher SOD and CAT activity relative to heat-sensitive ones under heat stress. Several studies indicated that the difference in abiotic stress tolerance may be partially resulted from constitutive antioxidant enzyme activities (Stepien and Klobus, 2005; Türkan et al., 2005). SOD and 
A

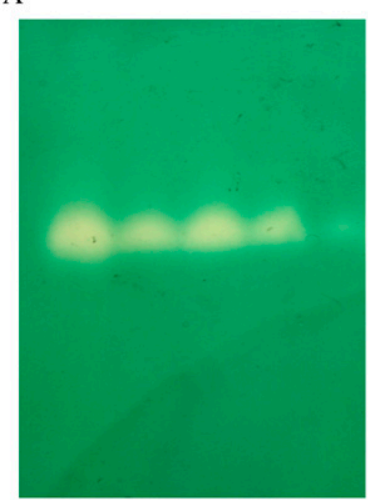

B

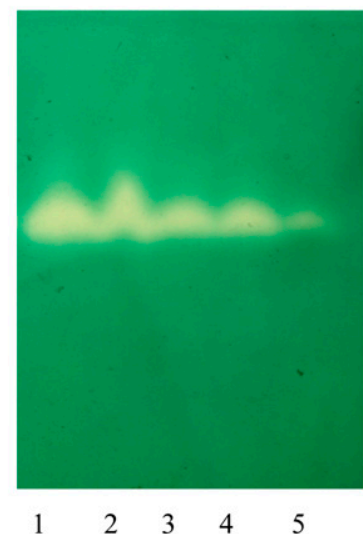

CAT1

Fig. 5. Changes in catalase (CAT) isoforms of 'Kenblue' (A) and 'EverGlade' (B) kentucky bluegrass during heat stress. Equal amounts $(15 \mu \mathrm{L})$ were loaded in each lane: lane $1=20^{\circ} \mathrm{C}(0 \mathrm{~d}$ of heat stress $)$, lane $2=38 / 30{ }^{\circ} \mathrm{C}$ for $7 \mathrm{~d}$, lane $3=38 / 30{ }^{\circ} \mathrm{C}$ for $14 \mathrm{~d}$, lane $4=38 / 30{ }^{\circ} \mathrm{C}$ for $21 \mathrm{~d}$, lane $5=38 / 30{ }^{\circ} \mathrm{C}$ for $28 \mathrm{~d}$.

CAT are two major ROS-scavenging enzymes (Smirnoff, 1993). SOD and CAT activity may increase in response to ROS accumulation at early stage of heat stress. As heat stress progresses, the SOD and CAT activity may decrease because of ROS-mediated damage to cell function, including lipid peroxidation of cell membranes. Decline of SOD and CAT activity occurred at $21 \mathrm{~d}$ for 'EverGlade' and at $14 \mathrm{~d}$ in 'Kenblue'. The high-level SOD and CAT activity sustained $7 \mathrm{~d}$ longer in 'EverGlade' relative to 'Kenblue' under heat stress. This suggests that the heat-tolerant cultivar may have greater ROS-scavenging capacity to suppress ROS-induced injury during heat stress.

Enzyme isoforms could be more sensitive or meaningful for interpreting plant responses to heat stress compared with total activity changes because different isoforms may function differently as a result of their distinct properties such as being stress inducible or not and having different subcellular locations (Apel and Hirt, 2004; Blokhina et al., 2003). In this study, 'EverGlade' showed two more SOD isoform bands (SOD5, SOD6) relative to 'Kenblue'. The additional isozymes could be involved in scavenging ROS produced during heat stress. The SOD2 isozymes have been found in the cytoplasm in pea (Pisum sativum L. cv. Alaska) leaves (Foster and Edwards, 1980).

It has been reported that abiotic stresses may induce CAT isozymes in various plant species (Lee and An, 2005). A transient increase in CAT isozymes was observed in NaCl-treated
A

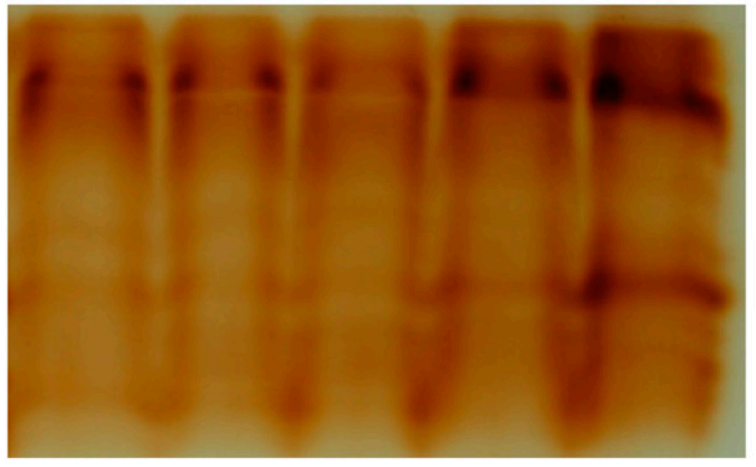

POD1

B

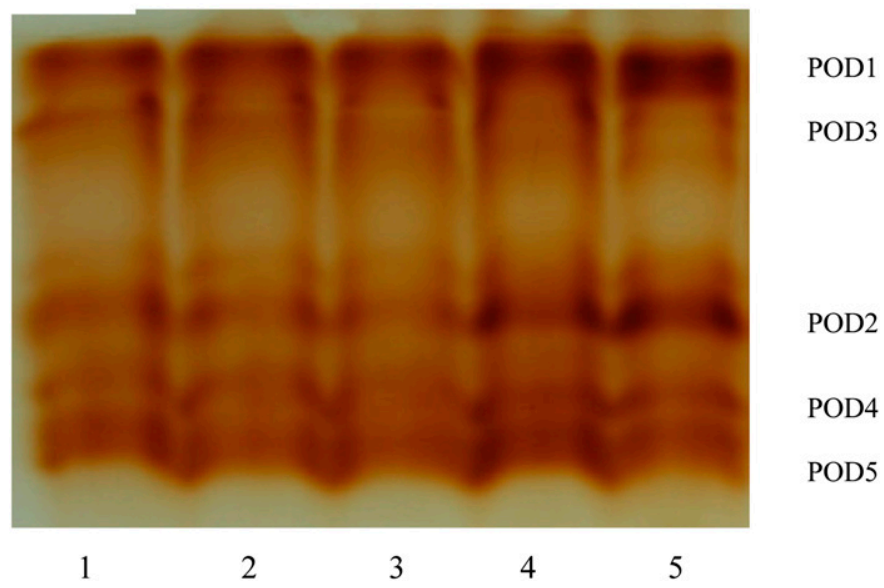

Fig. 6. Changes in peroxidase (POD) isoforms of 'Kenblue' (A) and 'EverGlade' (B) kentucky bluegrass during heat stress. Equal amounts $(15 \mu \mathrm{L})$ were loaded in each lane: lane $1=20^{\circ} \mathrm{C}(0 \mathrm{~d}$ of heat stress $)$, lane $2=38 / 30^{\circ} \mathrm{C}$ for $7 \mathrm{~d}$, lane $3=38 / 30{ }^{\circ} \mathrm{C}$ for $14 \mathrm{~d}$, lane $4=38 / 30{ }^{\circ} \mathrm{C}$ for $21 \mathrm{~d}$, lane $5=38 / 30{ }^{\circ} \mathrm{C}$ for $28 \mathrm{~d}$.

barley (Hordeum vulgare L.) root and shoot (Kim et al., 2005). In the present study, only the isozyme of CAT was identified in both cultivars. Greater abundance of the CAT isozyme detected in 'EverGlade' during heat stress coincided with the higher CAT activity in 'EverGlade' relative to 'Kenblue'. The reduction of CAT1 in both cultivars corresponded to the reduction of CAT activity at $28 \mathrm{~d}$ of heat stress. This is in general agreement with the results from He and Huang (2010) in kentucky bluegrass.

'EverGlade' had five POD isozymes and 'Kenblue' had only two POD isozymes. He and Huang (2010) detected eight POD isozymes in kentucky bluegrass subjected to heat stress. Wang et al. (2012) reported enhanced POD activity and two newly induced POD isoforms in creeping bentgrass under high temperature. In contrast, Liu et al. (1995) reported a decline in the intensity of a POD isoform in wheat (Triticum aestivum L.) seedlings in response to heat stress. In addition, Yin et al. (2008) found a POD isoform in lily (Lilium longiflorum L.) increased at 37 and $42{ }^{\circ} \mathrm{C}$ but decreased at $47^{\circ} \mathrm{C}$. These contradictory results may be the result of differences in heat stress tolerance among plants and differences in stress intensity and duration. The higher POD activity and more isozymes in 'EverGlade' relative to 'Kenblue' may be associated with its greater heat tolerance.

The results of this study indicated that POD activity declined and then increased, and 'EverGlade' had higher POD activity 

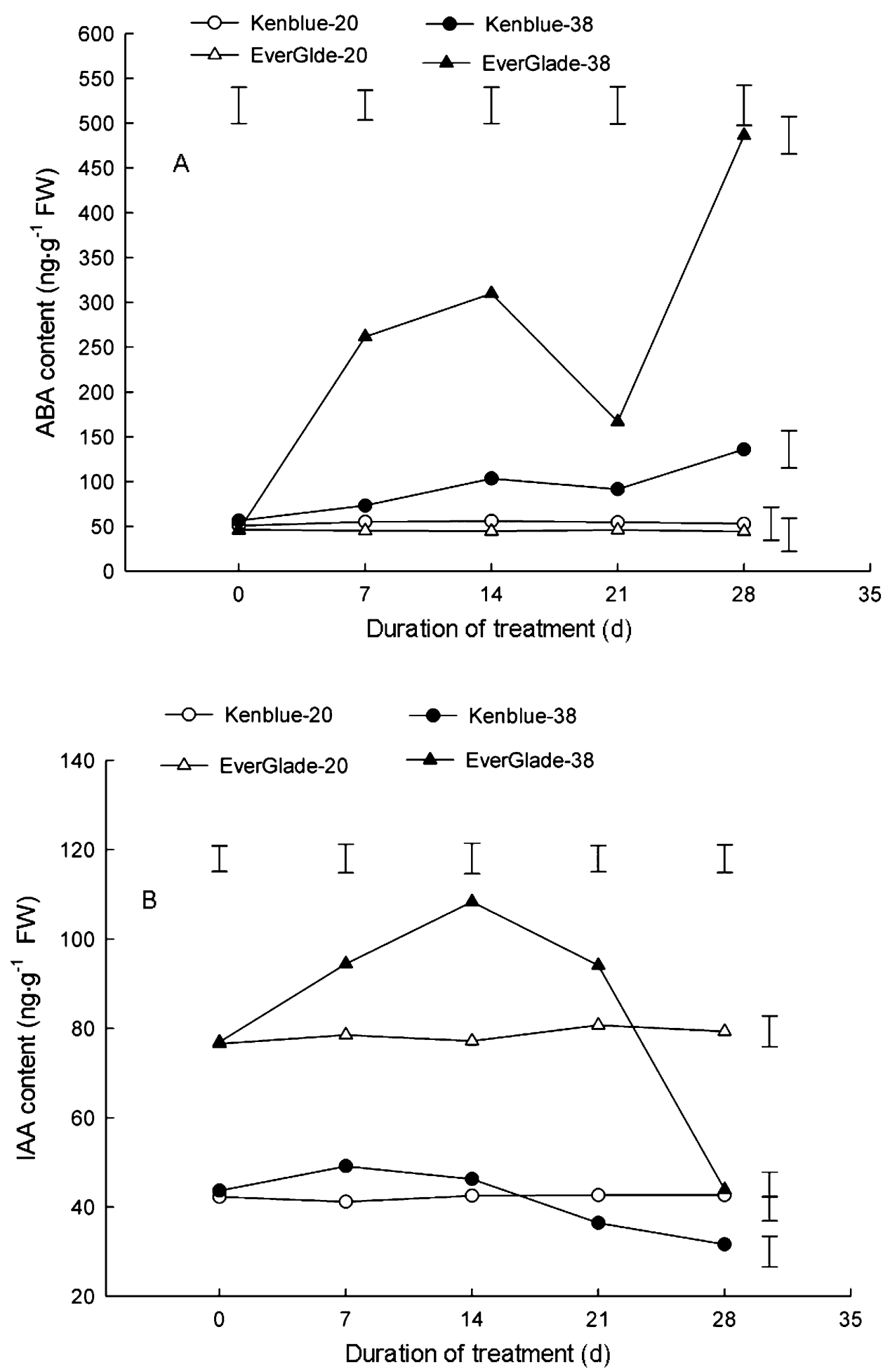

Fig. 7. Changes in leaf abscisic acid [ABA (A)] and indole-3-acetic acid [IAA (B)] content of two kentucky bluegrass cultivars during heat stress. Bars on the top indicate least significant difference (LSD) values $(P=0.05$, $\mathrm{n}=4$ ) for comparison among cultivars and on the right represent LSD values for comparison between duration of heat stress for a given cultivar. Kenblue-20 and Kenblue-38 indicate 'Kenblue' under normal condition and heat stress, respectively; EverGlade-20 and EverGlade-38 indicate 'EverGlade' under normal condition and heat stress, respectively.

relative to 'Kenblue' under heat stress. In addition, POD activity started to increase at $7 \mathrm{~d}$ in 'EverGlade' and at $14 \mathrm{~d}$ in 'Kenblue'. Zhang et al. (2009) reported that POD activity in zoysiagrass (Zoysia japonica Steud.) decreased after $6 \mathrm{~d}$ of heat stress. POD activity may be suppressed by accumulation of ROS at the early stage ( 0 to $14 \mathrm{~d}$ ) of heat stress and recover as POD gene expression increases in response to heat stress.

The results of this study indicated that APX activity tended to decline from 7 to $14 \mathrm{~d}$ and then increased from 14 to $28 \mathrm{~d}$. 'EverGlade' maintained higher POD activity than 'Kenblue' during heat stress. The results suggest that APX activity may more effective in scavenging $\mathrm{H}_{2} \mathrm{O}_{2}$ under prolonged heat stress relative to CAT whose activity declined at the late stage of heat stress. Cui et al. (2006) also found heattolerant tall fescue had higher APX and SOD activities compared with susceptible specie under heat stress. The results of this study indicate that the heat-tolerant cultivar had a greater ability of scavenging ROS than a heat-sensitive one under heat stress.

The results of this study showed that ABA content increased in response to heat stress with greater ABA content in 'EverGlade' relative to 'Kenblue' under heat stress. This is in agreement with a previous study by Xu and Huang (2006) that showed that $\mathrm{ABA}$ content drastically increased at $14 \mathrm{~d}$ of heat treatments in creeping bentgrass. The accumulation of ABA in response to heat shock and other stresses has been reported in several plant species, including maize (Zea mays L.), durum wheat (Triticum durum Desf.), and pea (Musatenko et al., 2003; Shakirova et al., 1995; Veselov et al., 1998). Wang et al. (2005) found ABA content significantly increased in grape within $1 \mathrm{~h}$ after high-temperature stress. The higher ABA content in 'EverGlade' relative to 'Kenblue' under heat stress suggested that ABA level may be associated with heat tolerance in kentucky bluegrass.

The results of this study showed that 'EverGlade' had higher IAA content when compared with 'Kenblue'. No previous study with turfgrass species was reported on IAA associated with heat stress tolerance. Zhang et al. (2009) found the tall fescue with higher IAA content has greater drought tolerance. Pustovoitova and Zholkevich. (1992) suggested that not only ABA, but also IAA is involved in the development of defense responses during the adaptation to drought. It was reported that IAA can delay plane 
senescence under stress (Zhang et al., 2009). This suggests that the cultivar with relatively higher IAA content may have greater heat tolerance than the one with less IAA content under heat stress.

In summary, heat stress [38/30 ${ }^{\circ} \mathrm{C}$ (day/night)] caused damage to kentucky bluegrass as leaf EL and MDA content increased. 'EverGlade' had less EL and MDA content relative to 'Kenblue' under heat stress. SOD and CAT activity increased and then declined during heat stress. POD and APX declined and then increased during heat stress. 'EverGlade' had greater activities of SOD, CAT, POD, and APX relative to 'Kenblue' under heat stress. In addition, 'EverGlade' had more SOD isozymes relative to 'Kenblue' under heat stress. Leaf ABA increased in response to heat stress. Leaf IAA increased and then declined during heat stress. 'EverGlade' had higher ABA and IAA content relative to 'Kenblue'. The results of this study indicated that antioxidant enzymes and the hormones (ABA and IAA) were associated with heat tolerance in kentucky bluegrass. The results suggest selection and use of cultivars with greater antioxidant enzyme activities and higher ABA and IAA level under heat stress may be a practical approach to improve kentucky bluegrass heat tolerance and growth.

\section{Literature Cited}

Almeselmani, M., P.S. Deshmukh, R.K. Sairam, S.R. Kushwaha, and T.P. Singh. 2006. Protective role of antioxidant enzymes under high temperature stress. Plant Sci. 171:382-388.

Apel, K. and H. Hirt. 2004. Reactive oxygen species: Metabolism, oxidative stress, and signal transduction. Ann. Rev Plant Biol. 55:373-399.

Beard, J.B. 1973. Turfgrass science and culture. Prentice Hall, Englewood Cliffs, NJ.

Beauchamp, C. and I. Fridovich. 1971. I. Superoxide dismutase: Improved assays and an assay applicable to acrylamide gels. Anal. Biochem. 44:276-287.

Blokhina, O., E. Virolainen, and K.V. Fagerstedt. 2003. Antioxidants, oxidative damage and oxygen deprivation stress: A review. Ann. Bot. (Lond.) 91:179-194.

Blum, A. and A. Ebercon. 1981. Cell membrane stability as a measure of drought and heat tolerance in wheat. Crop Sci. 21:43-47.

Chance, B. and A.C. Maehly. 1995. Assay of catalases and peroxidases. Methods Enzymol. 2:764-775.

Cui, L.J., R. Cao, J.L. Li, L.S. Zhang, and J.Z. Wang. 2006. High temperature effects on $\mathrm{d} /$ different heat susceptibility. Plant Growth Regulat. 49:127-136.

DiPaola, J.M. and J.B. Beard. 1992. Physiological effects of temperature stress, p. 231-262. In: Waddington, D.V., R.N. Carrow, and R.C. Shearman (eds.). Turfgrass. Agron. Monogr. 32. Amer. Soc. Agron., Madison, WI.

Edlund, A., S. Eklof, B. Sundberg, T. Moritz, and G. Sandberg. 1995. A microscale technique for gas chromatography-mass spectrometry measurements of picogram amounts of indole-3-acetic acid in plant tissues. Plant Physiol. 108:1043-1047.

Fielding, J.L. and J.L. Hall. 1978. A biochemical and cytochemical study of peroxidase activity in roots of Pisum sativum. I: A comparison of DAB-peroxidase and guaiacolperoxidase with particular emphasis on the properties of cell wall activity. J. Expt. Bot. 29:969981.

Foster, J.G. and G.E. Edwards. 1980. Localization of superoxide dismutase in leaves of C3 and C4 plants. Plant Cell Physiol. 21:895906.

Fry, J.D. and B. Huang. 2004. Applied turfgrass science and physiology. Wiley, New York, NY.

Giannopolitis, C.N. and S.K. Ries. 1977. Superoxide dismutase. 1. Occurrence in higher plants. Plant Physiol. 59:309-314.
He, Y.L. and B. Huang. 2010. Differential responses to heat stress in activities and isozymes of four antioxidant enzymes for two cultivars of kentucky bluegrass contrasting in heat tolerance. J. Amer. Soc. Hort. Sci. 135:116-124.

Hodges, D.M., J.M. Delong, C.F. Forney, and R. Prange. 1999. Improving the thiobarbituric acid-reactive-substances assay for estimating lipid peroxidation in plant tissues containing anthocyanin and other interfering compounds. Planta 207:604-611.

Huang, B. and H. Gao. 2001. Growth and carbohydrate metabolism of creeping bentgrass cultivars in response to increasing temperatures. Crop Sci. 40:1115-1120.

Jiang, Y. and B. Huang. 2001. Drought and heat stress injury to two cool-season turfgrasses in relation to antioxidant metabolism and lipid peroxidation. Crop Sci. 41:436-442.

Kim, S.Y., J.H. Lim, M.R. Park, Y.J. Kim, T. Park, Y.W. Seo, K.G. Choi, and S.J. Yun. 2005. Enhanced antioxidant enzymes are associated with reduced hydrogen peroxide in barley roots under saline stress. J. Biochem. Mol. Biol. 38:218-224.

Larkindale, J. and B. Huang. 2004. Thermo-tolerance and antioxidant systems in Agrostis stoloifera: Involvement of salicylic acid, abscisic acid, calcium, hydrogen peroxide, and ethylene. J. Plant Physiol. 161:405-413.

Lee, S.H. and C.S. An. 2005. Differential expression of three catalase genes in hot pepper (Capsicum annuum L.). Mol. Cell 20:247-255.

Liu, L., K. Yu, and S. Hao. 1995. Effect of temperature on peroxidase (POD) isozymes in winter wheat seedlings. Acta Agriculturae Boreali Sinica 10:59-64.

Liu, X.H., B. Huang, and G. Banowetz. 2002. Cytokinin effects on creeping bentgrass responses to heat stress: I. Shoot and root growth. Crop Sci. 42:457-465.

Liu, X.Z. and B. Huang. 2000. Heat stress injury in relation to membrane lipid peroxidation in creeping bentgrass. Crop Sci. 40:503-510.

Man, D., Y.X. Bao, L.B. Han, and X.Z. Zhang. 2011. Drought tolerance associated with proline and hormone metabolism in two tall fescue cultivars. HortScience 46:1027-1032.

Mullineaux, P.M. and G.P. Creissen. 1997. Glutathione reductase: Regulation and role in oxidative stress, p. 667-713. In: Scandalios, J.G. (ed.). Oxidative stress and the molecular biology of antioxidant defenses. Cold Spring Harbor Laboratory Press, New York, NY.

Musatenko, L.I., N.P. Vedenicheva, V.A. Vasyuk, and V.N. Generalova. 2003. Phytohormones in seedlings of maize hybrids differing in their tolerance to high temperature. Russ. J. Plant Physiol. 50:499-504.

Pinhero, R.G., M.V. Rao, G. Paliyath, D.P. Murr, and R.A. Fletcher. 1997. Changes in activities of antioxidant enzymes and their relationship to genetic and paclobutrazol-induced chilling tolerance of maize seedlings. Plant Physiol. 114:695-704.

Pustovoitova, T.N. and V.N. Zholkevich. 1992. Basic trends in the investigation of heat effects on physiological processes in plants. Fiziologiya i Biokhimiya Kul'turnykh Rastenii 24:14-27.

Shakirova, F.M., M.V. Bezrukova, and I.F. Shayakhmetov. 1995. The effect of heat-shock on the accumulation of ABA and lectin in wheat callus cells. Russ. J. Plant Physiol. 42:621-623.

Smirnoff, N. 1993. The role of active oxygen in the response of plants to water-deficit and desiccation. New Phytol. 125:27-58.

Stepien, P. and G. Klobus. 2005. Antioxidant defense in the leaves of C3 and C4 plants under salinity stress. Physiol. Plant. 125:31-40.

Strivastava, L.M. 2002. Plant growth and development: Hormones and environment. Academic Press, San Diego, CA.

Tang, R.S. and J. Zheng. 2008. Possible correlation between high temperature induced floret sterility and endogenous levels of IAA, GAs and ABA in rice (Oryza sativa L.). Plant Growth Regulat. 54:37-43. Türkan, I., M. Bor, F.O. Zdemir, and H. Koca. 2005. Differential responses of lipid peroxidation and antioxidants in the leaves of drought-tolerant $P$. acutifolius Gray and drought-sensitive $P$. vulgaris L. subjected to polyethylene glycol mediated water stress. Plant Sci. 168:223-231. 
Upchurch, R.G. 2008. Fatty acid unsaturation, mobilization, and regulation in the response of plants to stress. Biotechnol. Lett. 30:967-977.

Veselov, A.P., V.P. Lobov, and L.N. Olyunina. 1998. Phytohormones during heat shock and recovery. Russ. J. Plant Physiol. 45:611616.

Wang, C., A. Yang, H. Yin, and J. Zhang. 2008. Influence of water stress on endogenous hormone contents and cell damage of maize seedlings. J. Integr. Plant Biol. 50:427-434.

Wang, K.H., X.Z. Zhang, and E.H. Erik. 2012. Antioxidative responses in roots and shoots of creeping bentgrass under high temperature: Effects of nitrogen and cytokinin. J. Plant Physiol. 169:492-500.

Wang, L.J., W.D. Huang, Y.P. Liu, and J.C. Zhan. 2005. Changes in salicylic and abscisic acid contents during heat treatment and their effect on thermotolerance of grape plants. Russ. J. Plant Physiol. 52:516-520.

Wang, Z. and B. Huang. 2004. Physiological recovery of kentucky bluegrass from simultaneous drought and heat stress. Crop Sci. 44:1729-1736.

Weiler, E.W., P.S. Jordan, and W. Conrad. 1981. Levels of indole-3acetic acid in intact and decapitated coleoptiles as determined by a specific and highly sensitive solid-phase enzyme immunoassay. Planta 153:561-571.
Woodbury, W.A., K.S. Spencer, and M.A. Stahmann. 1971. An improved procedure using ferricyanide for detecting catalase isozymes. Anal. Biochem. 44:301.

Xiong, L.M., K.S. Schumaker, and J.K. Zhu. 2002. Cell signaling during cold, drought, and salt stress. Plant Cell 14:S165-S183.

$\mathrm{Xu}, \mathrm{Q}$. and B. Huang. 2006. Seasonal changes in root metabolic activity and nitrogen uptake for two cultivars of creeping bentgrass. HortScience 41:822-826.

Yin, H., Q.M. Chen, and M.F. Yi. 2008. Effects of short-term heat stress on oxidative damage and responses of antioxidant system in Lilium longiflorum. Plant Growth Regulat. 54:45-54.

Zhan, D., X.B. Sun, X.H. Puyang, and L.B. Han. 2012. A comparison of heat stress tolerance among 16 kentucky bluegrass cultivars. Chinese J. Grassland 34:54-59 [in Chinese].

Zhang, X.Z. and E.H. Ervin. 2008. Impact of seaweed extract-based cytokinins and zeatin riboside on creeping bentgrass heat tolerance. Crop Sci. 48:364-370.

Zhang, X.Z., E.H. Ervin, G.K. Evanylo, and K.C. Haering. 2009. Impact of biosolids on hormone metabolism in drought-stressed tall fescue. Crop Sci. 49:1893-1901.

Zhang, X.Z., E.H. Ervin, and R.E. Schmidt. 2005. The role of leaf pigment and antioxidant levels in UV-B resistance of dark-and lightgreen kentucky bluegrass cultivars. J. Amer. Soc. Hort. Sci. 130:836841. 